\title{
Dental and Oral Health Care Coverage for Seniors in the United States
}

\author{
Margaret Scarlett* \\ DMD, CAPT. (ret.), USPHS, CDC, USA \\ *Corresponding author: Margaret Scarlett, DMD, CAPT. (ret.), USPHS, CDC, USA
}

\begin{tabular}{|c|c|}
\hline ARTICLE INFO & ABSTRACT \\
\hline & $\begin{array}{l}\text { Citation: Margaret Scarlett. Dental and Oral Health Care Coverage for Seniors in the } \\
\text { United States. Biomed J Sci \& Tech Res 39(1)-2021. BJSTR. MS.ID.006253. }\end{array}$ \\
\hline
\end{tabular}

\section{Introduction}

Oral health is a key component of general health. Estimated prevalence of oral health problems is a staggering $50 \%$ worldwide [1]. In addition, diseases of the mouth have been associated with serious chronic diseases, especially among elderly adults [2]. In the US, federal legislators are currently debating proposals to expand Medicare, the public insurance for adults over age 65, to provide dental, vision and hearing benefits. However, these proposals raise both cost and feasibility concerns. Interim steps can be undertaken now to facilitate planning for providing dental benefits to seniors in public insurance schemes.

\section{Health Impact of Oral Disease}

Chronic diseases correlated with poor oral health range from diabetes and heart disease to arthritis, and mouth pain interferes with eating which, in turn, causes nutritional deficits that impact overall health [2]. Also, tooth loss is disfiguring, with mental health sequelae, such as shame, isolation and loss of self-esteem. All these problems are more common and more severe among older individuals, especially those with disabilities and among racial/ ethnic minorities or low socioeconomic groups. Assessing the true extent of the problem is hampered by a lack of outcome measure standardization and reliability [3]. This knowledge gap creates an evidence vacuum, likely to be filled by political agendas and shortterm cost considerations.

\section{Current Policy Debate}

The Build Back Better Act of 2021 includes vision, hearing and dental benefits for seniors as part of a $\$ 3.5$ Trillion spending bill for health and other topics. By September 16, the proposal had passed in two committees of the House of Representatives that are on the pathway to a full House vote. Unresolved issues include the fact that many low-income seniors are covered by Medicaid, instead of Medicare, and some states have not extended Medicaid dental coverage to all eligible residents. In addition, the Congressional Budget Office estimated that the cost of providing dental benefits would be higher than the costs for vision and hearing services ( $\$ 238$ Billion over 10 years for oral health for seniors, versus $\$ 30$ billion for vision care and $\$ 89$ Billion for hearing benefits). This led to provisions that phase-in coverage for dental treatment beginning in 2028. Additionally, debate between public health advocates for seniors and representatives of private practice dentistry center on whether patients and providers would actually participate in a public system, and about the feasibility of new government regulations [4,5]. One example of a regulatory barrier is that medical practice is reimbursed via diagnostic codes, but dental practices are typically reimbursed via treatment codes.

\section{Interim Policy Options}

If it is not possible to provide oral health benefits for all seniors now, then demonstration projects could focus on what works 
for seniors and private practice dentists. This applied research could be overseen collaboratively by health agencies and the US Small Business Administration. The projects should research the impact of various payment models (e.g., fee-for-service vs. Valuebased care) among small dental businesses in major regions of the country. Primary outcome measures would be cost efficiency, cost effectiveness and participation rates of both seniors and dental providers. Secondary study aims might be reliability of treatment outcome measures for dental function, esthetics, disease, and comfort, especially in high-risk seniors and those with disabilities.

\section{Conclusion}

US seniors have an urgent need for dental and oral health care. The minimum policy response would be research conducted now to pave the way for a workable system of dental coverage by 2028 . Given the increasingly clear connection between oral health and

\section{ISSN: 2574-1241}

DOI: 10.26717/BJSTR.2021.39.006253

Margaret Scarlett. Biomed J Sci \& Tech Res

(C) (P) This work is licensed under Creative

Submission Link: https://biomedres.us/submit-manuscript.php overall health, some of these projects should be cost-effectiveness studies with both oral and general health outcomes. Investments in oral health today may not only save money on overall health costs in the long run, but improve the quality of life, and may even save the lives of seniors.

\section{References}

1. (2018) Global, regional, and national incidence, prevalence, and years lived with disability for 354 diseases and injuries for 195 countries and territories, 1990-2017: a systematic analysis for the Global Burden of Disease Study 2017. Lancet 2018; 392: 1789-8583.

2. Centers for Disease Control and Prevention. Division of Oral Health. Fact Sheet on Older Adults.

3. Scarlett M, Kreps GM (2016) Oral Health Promotion [in] Introduction to Health Promotion, Zimmerman RS, DiClemente RJ, Andrus JK, \& Hosein EN (Eds.), 2016: 383-412.

4. (2021) Statement of the Oral Health Coalition. Accessed 9/22/2021.

5. (2021) American Dental Association. Accessed 9/22/2021.

$\begin{array}{ll}\text { BIOMEDICAL } & \text { Assets of Publishing with us } \\ \text { RESEARCHES } & \text { - Global archiving of articles } \\ \text { - Immediate, unrestricted online access }\end{array}$

